\title{
Poesia proletária ou berreta: trabalho e dinheiro em algumas poetas argentinas contemporâneas
}

\author{
Proletarian or berretian poetry: work and money \\ in some contemporary Argentinean poets
}

Joaquin Correa ${ }^{1}$

\begin{abstract}
Resumo:
Os restos da crise argentina que estourou em 2001 podem ser achados nos fundamentos das poéticas de Fernanda Laguna, Cecilia Pavón e Marina Yuszczuk, pertencentes à chamada geração dos anos de 1990. Com base numa leitura de Belleza y Felicidad interrelacionada com as condições precárias de vida no país depois da crise, o presente artigo pretende analisar um corpus poético vinculando os poemas com as questões trabalhistas (ou laborais) e monetárias para indagar essas consequências.
\end{abstract}

Palavras-chave: Poesia contemporânea. Dinheiro. Trabalho.

\begin{abstract}
:
The remains of Argentinean crisis that broke out in 2001 could be found in the substance of the poetics of Fernanda Laguna, Cecilia Pavón and Marina Yuszczuk, belonging to the so-called generation of the 1990s. Based on a reading of Belleza $y$ Felicidad interrelated with the precarious conditions of life in the country after the crisis, the present paper tries to analyze a poetic corpus linking poems with work and money to investigate these consequences.
\end{abstract}

Keywords: Contemporary poetry. Money. Work.

1 Formado em Letras pela Universidad Nacional de Mar del Plata (Argentina), é Mestre em Literaturas pela UFSC. Atual doutorando do Programa em Pós-graduação em Letras da UFSC. 
Em conversa com Ana Porrúa, Marcelo Díaz, membro do grupo de Poetas Mateístas de Bahía Blanca nos anos de 1990, afirmava sobre o conceito de berreta, fundamento de seu primeiro livro, editado em 1998 pela editora Libros de Tierra Firme: "Lo berreta es lo mismo que los nuevos ricos veneran como objetos kitsch, pero comprado en un todo $\mathrm{x}$ $2 \$ "$ (PORRÚA, 2008). A categoria do "berreta" daria a ver a avaliação dos objetos segundo apropriados por uma determinada classe. Conforme Ana Porrúa, "lo berreta tiene que ver con la pobreza también, con los márgenes del mercado, con lo que ya no tiene aura" (PORRÚA, 2008). E, se o primeiro livro de Díaz é Berreta, descobrimos ali uma poética que começa discutindo sua própria aura para, a partir disso, ler o panorama político imediato, aquela "normalidade inabitável” (DÍAZ, 2019, p. 2). Relendo pela lente berreta, Marcelo Díaz reescrevia célebres poemas de Rubén Darío, Wallace Stevens e Charles Baudelaire, fazendo de um dos animais tradicionais da poesia, o cisne, apenas um elemento degradado à decoração esquecida na mata do jardim, “[ú]nico sobreviviente / de un país difícil / en un tiempo difícil; / indiferente o digno, / a quién puede importarle" (DÍAZ, 2008, p. 11). O outrora galhardo símbolo da poesia, degradado a mero cimento berreta cagado pelos pombos, sai da alta poesia para ser parte de um cenário em ruínas.

O berreta esteve presente também no trabalho desenvolvido entre Fernanda Laguna e Cecilia Pavón em Belleza y Felicidad, galeria de arte, editora e espaço de circulação fundamental da segunda metade dos anos noventa em diante. O primeiro poema da obra reunida de Fernanda Laguna, Control o no control, chama-se Poesía Proletaria. Racconto do dia laboral, de uma duração de oito horas e quinze minutos, o poema descreve as vendas de materiais para pintura entregues em domicílio durante o transcurso do dia, anotando o dinheiro que a poeta, artista e galerista foi recebendo e os pareceres das pessoas com que ia se encontrando enquanto transitava a 
cidade de uma ponta para outra numa pequena moto. Ao recuperar o dia, o poema conta: conta o sucedido, conta o dinheiro recebido. $\mathrm{O}$ espaço do poema organiza, com uma sintaxe bastante simples, econômica, as anotações daquilo que sucedeu e dos ingressos de dinheiro que teve assim como os encargos para um futuro próximo que foram feitos pelas clientes que, por alguns indícios, aparecem como idosas da alta sociedade. Se da primeira dessas conversas anotou o seguinte:

\author{
En lo de Rosita vendí \\ varios bastidores, \\ algunos pinceles, \\ acrílicos.
}

Luego charlamos un ratito, me ofrecieron un café pero dije que no.

Hablamos acerca de Nueva York

que allí hay mucha plata, que es sucio pero que no les da vergüenza.

Que escribí, pinté y descansé. (LAGUNA, 2012a, p. 9).

Já a partir da segunda começará a elaborar um pensamento profissional:

Llegué y me atendió

la empleada

y me dijo:

- La señora ya viene.

Mientras esperaba pensaba en que podía vender mi cuerpo 
(hacer sexo)

para ganar más dinero

y no tener que cargar

tanto peso.

De todas formas

pensé,

“ahora también lo estoy vendiendo". (LAGUNA, 2012a, p.10)

Nesse mundo infantilizado que define a poesia de Fernanda Laguna, o pensamento é uma atividade desenvolvida apenas para ocupar o tempo e não tem uma densidade específica. O pensamento dela, lemos em "Optimismo", "ni siquiera es un pensamiento / es un divague automático de mierda" (LAGUNA, 2012d, p. 99). A artista pensa para preencher o vazio da espera que, segundo a cena, é produto de uma relação de poder. $\mathrm{O}$ fundamento do pensamento é meramente pragmático e carece de pathos: vou vender meu corpo para não carregar tanto peso como faço agora e ganhar, ao mesmo tempo, mais dinheiro. Contudo, antes da cliente em questão chegar, o raciocínio é abandonado ao compreender a identidade dos empregos: no delivery de materiais de pintura também está vendendo seu corpo. E, no entanto, não fecha explicitamente a equação; agora também se está prostituindo.

A interrupção ou abandono do raciocínio impede a identificação com a empregada (e incluso com as próprias prostitutas implícitas na comparação) que, se não fosse cínico ou paródico o título do poema, não seria chamada com essa denominação hierárquica e pejorativa, antes, seria considerada também ela uma "proletária" e constituiria um nós, as proletárias. $\mathrm{O}$ relato da atividade do dia a aproxima mais ao chamado 
"empreendedorismo". ${ }^{2}$ A recuperação brincalhona de uma palavra ancorada em décadas passadas, hoje quase propriedade exclusiva de setores minoritários radicalizados da esquerda, para definir o trabalho de venda de materiais de pintura e a posterior entrega em moto, caracterizados pelo "chiquitaje, menudeo, saldos, descuentos y ofertas" (BAEZA, 2017, p. 55), ultrapassa a inocência infantil e beira perigosamente o cinismo. Ou, desde outro ponto de vista, "es así como gran parte del léxico que en los sesenta y setenta apuntalaba consignas combativas queda ahora descolocado de los supuestos que lo sostenían" (KAMENSZAIN, 2016, p. 101), como afirma Tamara Kamenszain ao ler aos que escrevem com pouco, o que evidencia uma "memoria sin densidad - sin trauma, sin shock -"(KAMENSZAIN, 2016, p. 23), memória essa que, por sua vez, como consta na nota de rodapé, significaria uma mudança radical no coração da poesia, pelo menos tal e como Benjamin a descrevia a partir de Baudelaire, como uma experiência de choque. Em certa medida, por isso, esses escritores que ela chama "da intimidade" redefinem à intimidade longe dos malditos, do escândalo e do sacrifício, como "una tarea inclusiva, superficial y, se podría agregar a esta altura, inofensiva" (KAMENSZAIN, 2016, p. 45). Finalmente, Ana, a mulher rica, e até estrangeira pela escolha das palavras, deixa para ela $\mathrm{o}$ troco, sessenta centavos a mais, num gesto que transluz pena ou desprezo, embora ela fique feliz e saia da casa cantando uma música espontânea: "Quiero mi mujer con dinero, / que me venga / mi mujer con dinero" (LAGUNA, 2012a, p. 11).

Poesia proletária poderia ser um bom começo para considerar o trabalho de Marina Yuszczuk, quem, num pequeno texto de reminiscências pavesianas, Trabajar cans", reflexionava sobre seu próprio trabalho a partir das dores do corpo: “"Tenés la espalda de un estibador del puerto’ me dijo

"El sujeto del rendimiento, como empresario de sí mismo, sin duda es libre en cuanto que no está sometido a ningún otro que le mande y lo explote; pero no es realmente libre, pues se explota a sí mismo, por más que lo haga con entera libertad. El explotador es el explotado. Uno es actor y víctima a la vez. La explotación de sí mismo es mucho más eficiente que la ajena, porque va unida al sentimiento de libertad. Con ello la explotación también es posible sin dominio". (HAN, 2014, p.19-20). 
el cirujano que operó mi columna, y a mí me dio un poco de orgullo" (YUSZCZUK, 2012, p. 67). É o próprio corpo que evidencia a proximidade do trabalho da escrita com o trabalho braçal portuário, proletário por antonomásia, com base na configuração anatómica das costas. "Lavorare stanca. Y yo soy una chica que trabaja", acabará concluindo o texto. De algum modo, isso gera certa aproximação empática com os outros trabalhadores: "Me da culpa colarme, me da vergüenza que una vieja se ponga a aplaudir en la cola de la boletería del cine como vi el otro día, porque los empleados ganan poco y tienen frío" (YUSZCZUK, 2012, p. 83). Num poema posterior, que recupera a frase que impulsa à publicação em Facebook, “En qué estás pensando?”, a voz falante faz as contas e, ao redor do dinheiro, busca se compreender:

\author{
Gano 70 pesos \\ gasto 80 \\ en el trabajo tengo que dar vueltos \\ los cuento con terror \\ como si equivocarse fuera \\ criminal \\ no tengo obra social \\ estoy pensando qué puedo vender, un amigo me \\ dijo \\ que su computadora salió 7000 pesos \\ yo nunca compré nada que salga más de 1000 \\ pero tengo cantidad de ropa vieja \\ y una cuenta secreta \\ en mercadolibre \\ quisiera ser una buena comerciante \\ para ir a la feria americana \\ y vender esa campera de cuero \\ usada \\ que nunca quise usar \\ por mucho más de lo que la que pagué
}


hacer la diferencia

pero seguro que me van a embaucar

soy embaucable

y tengo miedo de la plata, soy tonta

porque le tengo miedo

y eso que vivo acá

en un lugar que tiene nombre de plata

donde todos hablamos de plata

todo el tiempo

ahora me tengo que ir

a calentar el almuerzo

en general

trato de que me salga rico

$\mathrm{y}$ de que no me salga

más de diez pesos. (YUSZCZUK, 2015, p. 10$11)$.

Evidentemente, as contas não fecham. Estamos no terreno da precariedade: o salário é baixo e não chega a cobrir as despesas diárias, o trabalho não proporciona os direitos sociais básicos e a vida está assentada na dúvida e na angústia. $O$ terror e o medo regem essa existência que, localizada num lugar com nome de dinheiro, seja La Plata, capital da província de Buenos Aires, seja a Argentina, como uma maldição, não permite se evadir dessa preocupação diária, da qual se fala o tempo todo. Esse olhar é o mesmo que depois irá observar os tênis na sua obsolescência planejada que rege a ordem das coisas ["duran re poco las converse, y eso / medio que es motivo de denuncia / de un mundo preparado / para que todo / todo / se rompa" (YUSZCZUK, 2015, p. 15)], que analisará a situação do casal a partir do vocabulário da economia bancária ["notá que dije cuenta, dije valor / sólo falta decir / confianza / inversión / y ya somos un banco / abierto / en épocas de crisis" (YUSZCZUK, 2015, p. 33)] ou que registrará o anseio dos homens maiores da família "de hacerse ricos, como si se 
tratara / de modos de vencer o mundo, su hostilidad, su determinación a hacernos pobres" (YUSZCZUK, 2015, p. 59). O olhar econômico que tomou conta do poema para ali ensaiar os números da sobrevivência se expande aos outros terrenos da vida diária.

Num poema incluído em Poesía geométrica, La flor de la vida, a voz do poema de Fernanda Laguna procura a flor da vida e, a partir desse desejo, acaba se identificando do seguinte modo:

\author{
Pido lo mínimo \\ como piden los mendigos de la calle \\ o te vendo como los del subte \\ este poema \\ a un deseo. (LAGUNA, 2012b, p. 45).
}

Recuperando essa poética do "chiquitaje, menudeo, saldos, descuentos y ofertas" (BAEZA, 2017, p. 55), Laguna associava a poeta aos mendigos da rua e o poema com aquelas coisinhas de pouco valor vendidas no metrô. Laguna, que manteve junto com Cecilia Pavón os preços das obras oferecidas em Belleza y Felicidad em pesos argentinos, diante da dolarizada economia do país, sabia, conforme afirma Federico Baeza, "que toda venta minorista es una venta sostenida en el cansancio y en el no control del tiempo, es una venta del cuerpo. Por eso el arte y la poesía son precisamente una sustracción del cuerpo a la economía de la subsistencia" (BAEZA, 2017, p. 155). Numa entrevista concedida em dezembro de 2007, na ocasião do fechamento de Belleza y Felicidad, Fernanda Laguna confessava:

Me citaban en exposiciones que se hacían en la Fundación Proa, o venían los alemanes de Ex Argentina, una muestra que paseaba por el mundo, y me decían que no entendían cómo podía hacer este arte cuando pasaban cosas como en 2001. Fue 
horrible: vivía con 200 pesos y no teníamos estufa; iba a Belleza con una camperota. Yo era la crisis. Ellos hacían todo con un montón de plata, armaban una obra que hablaba de la pobreza con una caja de acrílico llena de basura, y yo hacía un dibujito en un papel. Eso para mí era la revolución: poder hacer de la nada un valor. En arteBA, una vez, vendí miles de obras y saqué 3000 pesos. Puse todo en Eloísa Cartonera. ¿Ves esa magia? Con cinco días de feria abrí un local y aseguré seis meses de alquiler. (VILLA, 2007)

"Eu era a crise": era o econômico o que dava forma ao próprio modo de vida e os poemas como as obras artísticas eram parte disso. Rainha Midas, conforme Ana Porrúa, Laguna fazia "da banalidade um objeto precioso" (PORRÚA, 2002, p. 119). Nesse trabalho com o valor escasso, dado pela contingência, o acaso e a espontaneidade, Cecilia Palmeiro encontrava o excesso como característica de Belleza y Felicidad, que se opunha ao valor alto e falaz da cultura entendida como bem social: "La inmediatez respecto de la vida, que emerge como efecto de esta lógica, muestra en la apariencia de lo hecho sin esfuerzo y sin rigor una productividad coherente en cuyo valor final (bajísimo en dinero y estéticamente incontable) se observa un "precio justo, pero no literal"' (PALMEIRO, 2011, p.180). A venda do corpo é também a venda do poema que, como os objetos kitsch de Belleza y Felicidad, não possui quase nenhum valor em si, senão a posteriori, depois de reapropriados. Desse modo, os poemas também estão em pesos (ou patacones, lecop etc.) porque a dolarização faria ainda mais evidente sua carência de valor. A economia que o poema propõe está aquém do mínimo e é equiparável não ao Desejo e sim a um desejo, expressão desiderativa do infraleve. Assim, a economia do poema é a mesma com que em Baila se descreve as roupas de Gabriela [Bejerman]: "todo muy económico" (LAGUNA, 2012c, p. 85). A economia referida no "muito económico" é a própria da expressão "economizar" ou "fazer economia". Os poemas de 
Fernanda Laguna, nesse sentido, são muito económicos.

Num poema posterior, De ama de casa a mamá en casa, se considera o tempo de escrita do poema enquanto roubo ou diminuição do tempo noturno de descanso que, precisamente, uma mãe não tem. Dessa equação sairá uma poética:

\section{Y bueno...}

Hay que conformarse con lo que hay aunque una no sepa bien a lo que se está refiriendo.

Lo que hay es lo que hay

$\mathrm{y}$ en lo poco que hay

está contenido todo lo que hay en el universo. (LAGUNA, 2012e, p. 120).

O que há, do mesmo modo que o muito econômico, nomeia, paradoxalmente, a carência. A tautologia delimita um universo mínimo de coisas existentes que estão aí e nem se definem a priori como propriedades. Estão aí e, no entanto, também não estão muito disponíveis, nem como um objet trouvé, nem para fazer com elas uma obra conceitual ou da Money-art. O que há sempre é pouco, e se conformar com pouco é uma ética de vida da resignação ou do ascetismo. O que há é nada. $\mathrm{E}$ escrever é uma perda de tempo, tal e como lemos num verso de "A mi psicóloga ¿temporal? Gabriela Zigeler”, que numa das estrofes finais, sintomaticamente, declara: "y hoy es jueves y vivo / de un cuadro que vendí hace cinco meses" (LAGUNA, 2012f, p. 179). Dentro da arte então há diferencias: a escrita de poemas é uma perda do tempo ao passo que a pintura possibilita sobreviver.

No começo do primeiro poema do primeiro livro de Cecilia Pavón, ¿Existe el amor a los animales?, segundo a ordem das obras reunidas, já aparece a falta de dinheiro: "Mi casa se está poniendo antigua, / está 
envejeciendo, / las paredes se están descascarando y yo / no tengo plata para arreglarlas" (PAVÓN, 2012a, p. 9). A personificação que se adivinha no começo do poema e que muda a antiguidade da casa pela velhice faz desses reparos impossíveis cuidados necessários. A poeta não tem dinheiro para cuidar da própria casa, isto é, não possui um excedente de dinheiro que, além das despesas ordinárias, permita a ela dispor de uma quantidade $\mathrm{x}$ de dinheiro para recuperar o estado da casa.

Em A Fernanda, possessa pelo ar do mar que inunda a cidade, a poeta tem uma espécie de rapto alucinatório que, de modo onírico, a conduz à imaginação de uma festa organizada junto a Fernanda [Laguna], a quem está dedicado, desde o título, o poema em questão. $\mathrm{O}$ fechamento diz assim:

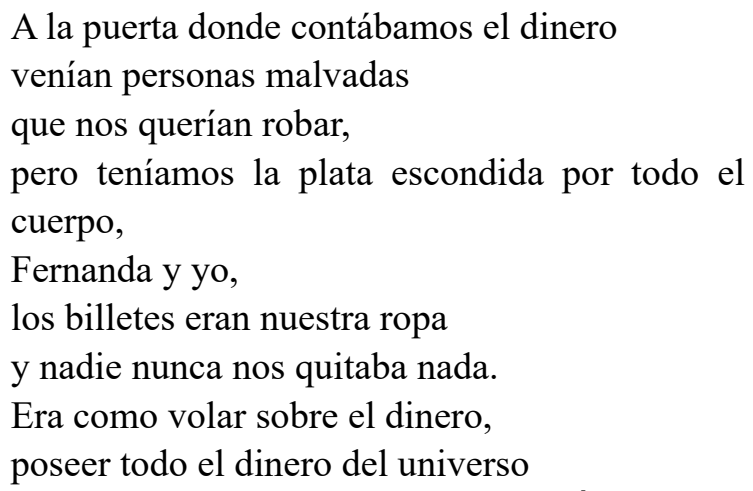
para repartirlo entre los pobres. (PAVÓN, 2012b, p. 37).

Do mesmo modo que em De ama de casa a mamá en casa, o dinheiro entra no poema graças à imaginação, e o relato da anedota é ancorado em gêneros não realistas (entre o relato de sonhos e uma narrativa infanto-juvenil). Até o próprio dinheiro é designado predominantemente através de sua forma menos corriqueira, mais formal, mais afastada do dia a dia: é "dinero" e não "plata". Nesse contexto, tanto as pessoas malvadas 
quanto os pobres possuem apenas o estatuto de personagens fictícios, seres imaginários. Tudo isso aparecerá explicitado em outro poema do livro, Nuevo libro, que se quer programático e está dedicado aos poetas, "que cada vez somos más" (PAVÓN, 2012b, p. 44):

La birome cayó estrepitosamente en el Hall y después se perdió.

Entonces, me va a resultar difícil escribir hoy. Aunque la poesía es algo puro y radical, algo fantástico, y no debería dejar de hacerla por nada del mundo.

Ni por el calor extremo ni por la pobreza que me impide viajar. (PAVÓN, 2012b, p. 44).

As qualidades atribuídas à poesia permanecem ainda próximas daquelas estabelecidas historicamente pelo romantismo (pura, radical e da ordem do fantástico, sobrenatural) e os últimos versos não deixam de lembrar a posição do poeta no jardim do rei burguês de Rubén Darío, mas ainda estão longe do Juan Lanas de ¿Por qué? ou do esfarrapado, mendigo, talvez um peregrino ou talvez um poeta de La canción de oro. No programa de Cecilia Pavón, os atributos que a poesia poderia usar como confronto com um estado de coisas determinado são obliterados pela estética kitsch, que apaga toda potência e a coloca na galeria de arte em pesos. Ao mesmo tempo, essa estética kitsch retira a poesia do imediato, impedindo que esse mundo da fantasia se defina como uma alternativa poética ao, por assim dizer, capital. A poesia é apenas uma atividade sobrevalorizada, sem valor.

$\mathrm{O}$ vaivém anímico que permeará os poemas de Caramelos de anís, de 2004, passa pelo econômico. Se, em La vida me sonríe, se sentira 
abençoada pela vida por ter achado 3500 euros esquecidos numa árvore, com os quais poderia viver na Europa seis meses sem trabalhar, benção que se estende ao resplendor do seu corpo no olhar dos outros e à fortuna de contar com o amor eterno do namorado cuja família é rica; já em Trendy armée, esse optimismo será totalmente o oposto a sua situação com o governo alemão que, negando seu visto de residência, nega a possibilidade de arrumar um emprego fixo, uma casa com as condições básicas de salubridade para morar e até um bom parceiro sexual: "Soy un fantasma, no puedo dejar de serlo. No trabajo, pero / tampoco estoy de vacaciones. El gobierno alemán no me / entregará un permiso de residencia" (PAVÓN, 2012c, p. 89). Definindo a vida no exterior a partir da economia, os poemas dão a ver o substrato econômico de toda vida.

No retorno ao país, num texto em forma de carta, Querida Kathrin:, índice daquilo que Cecilia Palmeiro denominou "lógica comunitária erotizada", formada pela amizade e o trabalho enquanto utopia nos poemas de Pavón (PALMEIRO, 2011, p. 240), por meio da comparação com os alemães, se critica a forma de dançar na cidade de Buenos Aires, pela falta de conexão com o próprio corpo, com o corpo do coletivo e pelo medo aos outros. Num momento, como negando o discurso de alguém ausente, cuja voz se recupera, diz: "Cada uno baila para sí. Casi todos mirando para abajo. Y además mal, como si le tuvieran miedo a la música. No es que esto haya empezado con la crisis. Esta actitud en la pista, ya estaba desde antes" (PAVÓN, 2012c, p. 80). A crise, embora apareça como o fantasma que percorre a cidade (cujos donos são os corretores da Bolsa, segundo pensa em voz alta em Art Décó), não é a causa da impermeabilidade dos corpos. Tampouco sabemos, mas podemos suspeitar, se não é a crise, também, a causa da venda dos vestidos de alta costura que alguém tinha dado para a falante de outro poema e que ele agora reclama em francês. A justificativa da venda, o resto do poema, também em francês, é tripartite: estava sozinha, não tinha nada para comer e morava num bairro punk em Buenos Aires. 
Em El Club en la Capital, a professora de yoga, no fechamento de uma de suas aulas e do poema, "El día después de los levantamientos populares dijo / 'el sábado hacemos una meditación universal / para pedir por la paz en el mundo"” (PAVÓN, 2012d, p. 100). O fantasma do momento crítico do país percorre essa coletânea de poemas de 2004 do princípio ao fim, mas emerge apenas a partir da recuperação da voz e discursos dos outros.

O valor das canetas está dado paradoxalmente por seu escasso valor. Figuras tão opostas como Néstor Kirchner ou Jair Bolsonaro fizeram questão de mostrar seu uso, num gesto tanto de antissolenidade quanto de aparente sobriedade, contrário simbolicamente dessa miragem contemporânea, a corrupção. No sentido popular, corriqueiro, desauratizado e até kitsch, aparece a caneta nos poemas de Cecilia Pavon, como o já citado Nuevo libro ou como ¿En qué alacena de qué cocina?

\section{¿Por qué valen tan poco mis palabras? quisiera que valieran oro, pero son gratis como la respiración, Escritas con birome roja son gratis como la sangre. (Pavón, 2012b, p. 44).}

Seguindo o método da caneta de César Aira (2002), a caneta é a figura metonímica da escrita da poeta e, por isso, da poeta e da poesia em si. A diferença das penas, as canetas não são um símbolo de status nem são únicas e intransferíveis. Desse modo, mediante o uso da caneta, a poeta perde na multidão sua aura, sua singularidade. $O$ valor das palavras da poeta já não é mais o valor do ouro. E nem quando materializadas pela escrita, já matéria do poema, adquirem valor. A caneta, nesse raciocínio, adequa-se à escrita do poema, porque custa pouco. Nem a respiração, nem o sangue, nem a palavra da poeta valem alguma coisa. E não só não valem nada, não pertencem a ela própria, são gratuitas, qualquer um pode ter aceso. O poema emagrece até virar, nos termos de Byung-Chul Han, transparente, não transcendente: "Las cosas se tornan transparentes 
cuando se despojan de su singularidad y se expresan completamente en la dimensión del precio. El dinero, que todo lo hace comparable con todo, suprime cualquier rasgo de lo inconmensurable, cualquier singularidad de las cosas" (HAN, 2013, p. 12). A poeta, desse modo, não possui alguma coisa que possa chamar de própria. E o tempo, medida do custo de qualquer escritor, se reduz drasticamente: o poema não custou trabalho algum para fazê-lo e, com isso, "la más valiosa de las monedas, el tiempo de la vida" (AIRA, 2003) perde sua força, dado que o gasto empregado em produzir o poema não é "tan exorbitante que induce a conservarlo y apreciarlo y atesorarlo" (AIRA, 2003).

Talvez a poética económica de Cecilia Pavón não apareça em outro lugar melhor do que em Es maravilloso gastar el dinero...:

Es maravilloso gastar el dinero cuando lo ganás con

facilidad. Como si fuera liviano, limpio, y como si estuvieras

haciéndole un bien al género humano, estos veinte dólares que

ahora salen de tu bolsillo pondrán en movimiento cientos de

industrias. Desde ahora esa bufanda verde con hilos dorados viaja

de la tienda a tu casa. El dinero hace que las cosas se muevan con

magia por la ciudad. Cosas que viajan en valijas. Lo único

importante de viajar es traer cosas. Los recuerdos son ilusiones,

los objetos, la única verdad que permanece, tiempo y dinero.

Cuando te mueras lo harás en tu cama, rodeada de objetos bellos 
y significativos, ropa de diseñadores talentosos, o libros de

fotografías con hojas pesadas. La ropa cara es la única que queda

bien. Los libros de los poetas jóvenes alemanes son hermosos y

son caros, las mecedoras de haya son hermosas y son caras, las

copas de cristal, los anillos de falso brillantes, el champagne. Ah, el

aire en los Alpes está como hecho de champagne! A esta altura,

nadie debería trabajar y todos deberían gastar; ah los dólares

alpinos! Si sacaran todo el dinero de los bancos suizos se

formarían montañas de francos suizos: Quisiera tener una

habitación llena de euros, desde el piso hasta el techo, entrar en la

madrugada cuando está todo oscuro y pisarlos; tomaría un

puñado sin mirar la cantidad y los pondría en los bolsillos de los

invitados, dormiría sobre los euros como si durmiera sobre el

heno de un establo. Protegida por la comunidad europea y sus

monumentos. (PAVÓN, 2012d, p. 108).

O dinheiro é um fluxo e suas manifestações (dólar, euro, franco suíço) estão além das fronteiras nacionais ou comunitárias. A visão ingênua do poema acaba descobrindo, como se fosse um passe de mágica, a engrenagem que aciona o fluxo do dinheiro, cujas qualidades parecem 
ser as próprias da água. Passa-se da liquidez do fluxo do dinheiro a sua materialidade mais absurda e, em todas as suas etapas, o dinheiro é lindo, puro, limpo. Assim, se o começo do poema estava dado pela felicidade do gasto de dinheiro possibilitado por um trabalho simples e eficaz no seu rédito imediato, tal e como líamos no poema de abertura de Reflexiones automáticas, de Fernanda Laguna, o final colocará em cena uma utopia: a atividade principal da vida deveria ser o gasto de dinheiro e não o trabalho. Abolindo o vínculo entre trabalho e dinheiro, quebrando a relação ali onde se define enquanto meio e fim, o poema autonomiza o trabalho, liberando-o da urgência monetária. O poema, veículo da utopia, será trabalho sem fim ou gasto sem causas. O poema será, então, um ato puro, pura consequência.

Numa crônica em El País, da Espanha, César Aira (2002) propunha pensar novos valores - porque os valores são históricos e os acontecimentos do dezembro de 2001 argentino tinham mudado nossa história - para os poetas de dezembro de 2001, como ele os chama, que exigiam uma redefinição da arte e da literatura desses tempos. A anedota que apresentava para fundamentar seu raciocínio eram os livrinhos de poesia, "gratuitos y fantasmales, accidentes de la Historia que ilustran ejemplarmente" (AIRA, 2002), que tinham sido impressos graças a promessa de um edital do Ministério da Cultura que, crise mediante, foi no melhor dos casos - pago muito a posteriori e com as editoras quebradas. Esse foi o caso, por exemplo, de Ediciones del Diego ou de Belleza y Felicidad ["el nombre es todo un programa de resistencia", dirá dela Aira (2002)]. Se "[a] arte acaba sempre por ser negociável, portanto aceitável; basta para isso confiná-la nos lugares que garantem sua guarda, ou seja, sua imunidade" (DIDI-HUBERMAN, 2019, p. 55), a garantia que o subsídio público dava a essas obras assegurava sua auratizacão. Porém, a irrupção da crise, a desvalorização da moeda e a quebra das editoras cortaram o caminho triunfal dos poetas e os poemas perderam ou, quanto menos, suspenderam seu poder aurático, aquele próprio do rei Midas de exercer 
uma auralização sobre seu entorno próximo. De todos modos, assegurava Aira, com os valores do passado, esses poemas eram uma fraude. Com os valores do presente, "estos poemas toman un color de necesidad" (AIRA, 2002). E se, como afirma Byung-Chul Han, “[e]l dinero es un objeto particular, puesto que es el valor" (HAN, 2016, p. 24), a proposta de Aira era similar a contemporânea dos Venus (STEGMAYER, 2017). Novas definições, novos valores: da fraude à necessidade esteve a monstruosa poesia da virada do século, obras sem rabo nem cabeça, que, como as diferentes moedas nacionais e estatais que começavam a circular naquela época, procurava ser outra forma de troca, moeda de escasso ou nulo valor, inestimável em todo caso, interrupção dos fluxos do tempo, busca do tempo usurpado e reconfiguração do futuro, acontecimento fulgurante apenas medido a plena perda, gratuito e fantasmal.

\section{Referências}

AIRA, César. Los poetas del 31 de diciembre de 2001. El País, 7 de fev. 2002. Disponível em: https://elpais.com/diario/2002/02/09/ babelia/1013215161_850215.html. Aceso em: 21 de maio de 2019.

. El método de la lapicera". El País, Acesso em: 11 out. 2003. Disponível em: https://elpais.com/diario/2003/10/11/ babelia/1065829158_850215.html. Substituir por: Acesso em: 21 maio 2019.

BAEZA, Federico. "Por nada". In: BORISONIK, Hernán. Soporte: el uso del dinero como material en las artes visuales. Buenos Aires: Miño y Dávila, 2017. p. 152-163.

DÍAZ, Marcelo. Berreta. Mar del Plata: Goles rosas, 2008.

. Poemas. ClimaCom - A Linguagem da Contingência, ano 6, n. 15,

p. 1-4, ago. 2019. Disponível em: http://climacom.mudancasclimaticas. net.br/marcelo-diaz-poemas/. Aceso em: 17 out.2019. 
DIDI-HUBERMAN, Georges. "Comemorar sobre o fio". In: . Sobre o fio. Tradução Fernando Scheibe. Desterro: Cultura e Barbárie, 2019. p. 25-90.

HAN, Byung-Chul. La sociedad de la transparencia. Tradução Raúl Gabás. Barcelona: Herder, 2013.

. La agonía del Eros. Tradução Raúl Gabás. Barcelona: Herder, 2014.

. Topología de la violencia. Tradução Paula Kuffer. Barcelona: Herder, 2016.

KAMENSZAIN, Tamara. Una intimidad inofensiva. Los que escriben con lo que hay. Buenos Aires: Eterna Cadencia, 2016.

LAGUNA, Fernanda. He venido a este planeta. In: . Control o no control. Poemas 1999-2011. Mansalva: Buenos Aires: 2012a. P. 7-36.

. Poesía geométrica. In: . Control o no control. Poemas 1999-2011. Mansalva: Buenos Aires: 2012b. p. 37-48.

. Ese momento del atardecer que no atardece jamás. In:

Control o no control. Poemas 1999-2011. Mansalva: Buenos Aires: 2012c. p. 83-96.

. He leído tan poco este año. In: . Control o no control. Poemas 1999-2011. Mansalva: Buenos Aires: 2012d. p. 97-114.

. El milagro de la nieve. In: . Control o no control. Poemas 1999-2011. Mansalva: Buenos Aires: 2012e. p. 115-132.

. Si un poema fuera nuestra casa. In: . Control o no control. Poemas 1999-2011. Mansalva: Buenos Aires: 2012f. p. 167-186.

PALMEIRO, Cecilia. Desbunde y felicidad: De la Cartonera a Perlongher. Buenos Aires: Título, 2011.

PAVÓN, Cecilia. ¿Existe el amor a los animales? In: Un hotel con mi nombre. Buenos Aires: Mansalva, 2012a. p. 7-32.

. Virgen. In: . Un hotel con mi nombre. Buenos Aires: Mansalva, 2012b. p. 33-57. 
- Caramelos de Anís. In: . Un hotel con mi nombre. Buenos Aires: Mansalva, 2012c. p. 73-103.

. Poema robado a Claudio Iglesias. In: . Un hotel con $m i$ nombre. Buenos Aires: Mansalva, 2012d. p. 105-116. . Hoy vi un cuadro. In: . Un hotel con mi nombre. Buenos Aires: Mansalva, 2012e. p. 117-132.

PORRÚA, Ana. Notas sobre a recente poesia argentina e suas antologias. Babel. Revista de Poesia, Tradução e Crítica, n. 5, p. 118-129, 2002.

- Contratapa a Berreta, de Marcelo Díaz. In: DÍAZ, Marcelo. Berreta. Mar del Plata: Goles rosas, 2008.

STEGMAYER, María. Bajo el signo de Venus: deseo, amistad, política en la Argentina post-2001. In: BORISONIK, Hernán. Soporte: el uso del dinero como material en las artes visuales. Buenos Aires: Miño y Dávila, 2017. p. 136-151.

VILLA, Javier. Final y felicidad. adn Cultura, La Nación, 29 dez. 2007. Disponível em: http://www.lanacion.com.ar/nota.asp?nota id=974095 Aceso em: 6 dez. 2019.

YUSZCZUK, Marina. Lo que la gente hace. Buenos Aires: Blatt \& Ríos, 2012.

. La ola de frío polar. Buenos Aires: Gog y Magog Ediciones, 2015.

Recebido em: 09/02/2020

Aprovado em: 23/06/2020 